\title{
Rankings, accreditations, and international exchange students
}

\author{
Gabriele Marconi
}

Correspondence: g.marconi@ maastrichtuniversity.nl Organization and Strategy, Maastricht University, Maastricht, The Netherlands

\begin{abstract}
Do international university rankings or professional accreditations affect the preferences of exchange students over different institutions? This paper investigates the question by analysing the determinants of Maastricht University School of Business and Economics (SBE) students' choices of possible destinations for their compulsory period of study abroad. The unique dataset used includes 2,970 applications for studying abroad between academic years 2004/2005 and 2008/2009, and 152 partner institutions across the world among which students can choose. A model is developed and estimated by means of the probit model. The results indicate that international rankings (the THESR) and business school accreditations (AACSB and EQUIS) are important for exchange students with high academic achievement, even after taking university fixed-effects into account. However, the estimated effect is small or even negative for students with lower academic achievement. As suggested by previous literature, also other characteristics of the university location (e.g. distance from the equator) affect students' choices.
\end{abstract}

JEL codes: $123-$ C 35

Keywords: International students; Higher education institutions; Rankings; Accreditations; Student choice

\section{Introduction}

When choosing a destination for a period of study abroad, students are expected to take a number of factors into consideration, such as price levels, climate, and the quality of the education. This paper investigates the role of these factors in students' choices, with a particular focus on education quality. As measures (or proxies) of quality the Times Higher Education Supplement Ranking (THESR) and the most wide-spread professional business schools accreditations (Association to Advance Collegiate Schools of Business, AACSB, and European Quality Improvement System, EQUIS) are used. This analysis investigates whether these measures affect prospective exchange students' choice of potential destinations. Accredited or well-ranked universities are expected to be preferred by students. This holds true if the student values the quality of education during her stay abroad, and if accreditations and rankings are a proxy for quality. Furthermore, there might be a causal effect: if the information about the potential host institutions available to students is incomplete, rankings and accreditations may work as a signal for quality. Besides quality of education, this 
paper also investigates whether other characteristics of the host institution affect students' choices.

International student mobility is of great interest to policy-makers, especially in Europe, because it is thought to foster, among other desired outcomes, labour mobility, the creation of a common labour market, cultural integration, and the creation of class of leaders at a European level (Ritzen, 2010; European Commission, 2009). Quality assurance in higher education is considered a crucial aspect to be improved at a European level to foster student mobility (European Commission, 2006). If existing measures of quality are considered reliable by mobile students, they can be used as a tool to foster mobility. Ritzen (2010) argues that Europe-wide accreditation by international professional organisations is a key step to improve quality assurance and reach appropriate levels of student mobility. The fact that quality differentials are a major determinant of international student mobility is well established in the literature on international students mobility (e.g. McMahon, 1992; Kelo, 2006; Thissen and Ederveen, 2006). However, how to adequately signal the quality of the education provided at different institutions remains an unresolved issue for education managers and policy-makers. As accreditations are expensive both in terms of time and monetary costs, it is crucial for education managers to understand whether they are actually considered a valuable signal by their stakeholders. Policy-makers and university managers should know whether students actually take rankings and accreditations into consideration.

The data used in this paper has been made available by Maastricht University School of Business and Economics (SBE), a large Dutch business school with more than 3,000 students. From administrative records, it is possible to identify SBE's partner institutions and the preferences of the prospective exchange undergraduate students over these institutions. The sample covers the period from the academic year 2004/2005 to 2008/2009, 152 universities, and 2,970 exchange applications. SBE's data is particularly suitable for the purposes of this study, as the faculty prides itself on a strong international orientation, and its students can choose among a diverse set of host institutions. Furthermore, the exchange period is compulsory for SBE students, so that it is possible to analyse the full population of prospective exchange students. On the other hand, generalising the results is difficult, as the data is based on only one institution.

In order to link the data to an estimation strategy, a model of whether a university is chosen by a particular student has been developed. Subsequently the appropriate variables to be included in the estimation on the basis of this model were identified. Finally, the model has been estimated using an ordinary probit model with and without university fixed-effects. The results suggest that the THESR rank has a causal effect on the choices of exchange students with high academic achievement. The number of accreditations also appears to have a large impact at the top of students' distribution, but the estimated coefficient is not significant when university fixed-effects are taken into account. The effect of the THESR and of accreditations is small for the median student, and it is negative for students with lower-than-average academic achievement. Other variables, such as gross national income (GNI) per capita or distance from the equator, appear to affect the preferences of exchange students as well. These results are consistent with the 
literature on ERASMUS students which used different methodologies (Teichler, 2004; Rodriguez-Gonzalez et al., 2011).

This paper is organised as follows. The next section reviews the literature on student choice and international exchange students; Section 3 describes the application process at SBE and the data; Section 4 develops the model and the empirical strategy; Section 5 presents the results; the last section concludes.

\section{Literature review}

To the knowledge of the author, this study is the first to analyse the determinants of exchange students' choice of institutions in other countries. The effect of university rankings on student choice has received some attention, but mostly in a national context. In general, it has not been determined yet whether rankings and accreditations influence the decisions of prospective students to apply to a given university. On the a whole, the literature on the flows of exchange students indicates that factors related to both, quality of education and other characteristics of the destination, play a role in students' decisions.

Prospective exchange students are enrolled at a university in a given country, and decide to spend a period of study (usually one semester) outside that country, at an institution linked to their home university through a partnership agreement (McInnis et al., 2004). Exchange students are likely to value the academic quality of the host institution. After all, they obtain a considerable part of their education (usually, one semester of six) at the host institution, and the exchange experience is expected to improve their skills and career prospects considerably (e.g. Bracht et al., 2006; Teichler and Janson, 2007). In addition, the returns to one year of education have been found to be higher for students attending prestigious colleges in the US (e.g. Brewer et al., 1999; Black and Smith, 2004). If rankings and accreditations are correlated with university quality, then we should observe that exchange students choose well-ranked or accredited universities more often. Furthermore, a causal effect is expected, as it is not easy for students to acquire information about the quality standards of foreign universities and university systems. Hence, accreditations and rankings could work as a signal for institutional quality.

Accreditations and rankings are both intended to signal the quality of the services offered by a university, but they work differently. A ranking on one hand consists of a contemporaneous analysis of a set of universities based on summary statistics. As such, they have been often criticised (see e.g. Marginson, 2007, for a critique of the THESR methodology; Saisana et al. 2011, for an evaluation on the reliability of different international rankings). However, they have an enormous impact in the landscape of higher education (Hazelkorn, 2008). On the other hand, an accreditation consists of "an evaluation of whether an institution qualifies for a certain status" (Woodhouse, 1999, p. 33). This evaluation is awarded after an in-depth analysis of a single institution and aims to establish: whether its objectives are appropriate; whether its plans are suitable to achieve the objectives; whether actions conform with the plans and whether they are effective; what is the measure of the objective (Lock, 1999; Woodhouse, 1999). The value of accreditations as an indicator of quality has been less controversial. Sciglimpaglia et al. (2005) gives an overview of the history of professional accreditations in the field of business education, noting their increasing relevance within the academic world. 
The literature on students' choice of different higher education institutions has been extensive. Many papers focus on the effect of tuition fees or distance from the closest college as determinants of students' choices (e.g. Soo and Elliott, 2010; Gibbons and Vignoles, 2012). Some works (e.g. Monks and Ehrenberg, 1999; Kong and Veall, 2002) investigate the relationship between a university's position in national rankings and students' applications to the university. These studies do not analyse the individual student choice, but the impact of rankings on measures such as the number of applicants to the institution or the average Scholastic Assessment Test (SAT) score of the students admitted to an institution. The results are contradictory. Drewes and Michael (2006) investigate the role of rankings in determining the choices of prospective students to apply to the 17 universities of the province of Ontario, Canada. They use a dataset that is very similar to the one used for this paper; they look at the application forms of prospective students who may choose a number of universities they would like to attend. They find mixed results: rankings appear to affect the probability of students choosing a university only in some fields of study, and in different ways. Only a few studies address the existence of a relationship between students' preferences and the position of a university in either of the two main worldwide rankings, the THESR and the Academic Ranking of World Universities (ARWU), or the status regarding one of the three main professional accreditations for business education, the Association to Advance Collegiate Schools of Business (AACSB), the European Quality Improvement System (EQUIS), and the Association of MBA (AMBA). Montgomery (2002), for example, includes the AACSB accreditation as a control variable in his empirical model of college choice. He uses a nested logit model to model the probability that a prospective student decides for a given business school or to look for a job instead. He finds that the level of accreditation is correlated with the probability of the student choosing the university, but he neither comments on the result, nor investigates whether the relationship could be causal. On the contrary, Elliott (2012), who analyses the effect of tuition fees on the number of applications controlling for accreditations, finds no impact of accreditations on international students' applications to British schools of business. In general, studies analysing the individual choice between universities have remained in the context of one country (for example, the aforementioned studies for the US, UK or Canada; or Oosterbeek et al., 1992, for the Netherlands). Therefore, it is an advantage of the data used in this paper that it allows to investigate the choices of a population of students across an international sample of universities.

Most of the studies on exchange students have focussed on Europe and, more specifically, on the ERASMUS Programme. The first studies appeared shortly after the inauguration of the Erasmus programme (e.g. Burn et al., 1990). Studies of the determinants of the choice of Erasmus students have usually made use of surveys and have focussed mainly on why students undertake a study period abroad, rather than on why they chose a particular university. For example, Teichler (2004, p. 397) reports some survey statistics and concludes that "students expect [...] academic, cultural, linguistic and professional benefits, but [...] combining them with an interesting extracurricular life during the period spent abroad". Rodriguez-Gonzalez et al. (2011) is perhaps the first study to examine the determinants of exchange (ERASMUS) students' choices of possible destinations in other countries, but they look at aggregate country flows. They 
find results broadly consistent with Teichler (2004): students seem to choose universities in countries with good educational systems (as measured by the proportion of universities listed in the ARWU top 200 universities), but also destinations with pleasant climate and touristic appeal (such as the Mediterranean countries). Price levels in the host country also appear to be taken into consideration by exchange students. Based on the results of their survey, Llewellyn-Smith and McCabe (2008) addressed the determinants of exchange students' destination choices, but focussed on students studying in Australia and on aspects other than the impact of international indicators for university quality. Their study confirms that factors such as cost of living or culture are important determinants of these choices.

\section{Data}

\section{Application process for an exchange period at SBE}

This paper uses data on the preferences of SBE students applying for a compulsory exchange period abroad. At SBE a study period abroad has been compulsory for all bachelor programmes since 2001. Around 600 students take part in exchanges every year, generating a total of 2,970 applications during the observation period, from the academic year 2004/2005 to 2008/2009. The application procedure that students have to comply with has changed over the years, but has maintained a number of common features. Firstly, the International Relations Office (IRO) of the faculty compiles a meritbased ranking of the students, based on the grade point average (GPA) and on other factors like the number of credits obtained by the student and the study programme which she is enrolled in. The students with the highest academic achievement top the IRO's ranking. As the second step, students fill in an application form, in which they are asked to indicate six partner institutions where they would particularly like to study. Then, students are allocated one of the partner institutions that they have listed in their application form by the IRO. Places are allocated based on availability after higherranked students have already been allocated a place. It follows that the highest-ranked student is sent to her favourite institution. The second-ranked is allocated to her favourite institution if the available places for that institution have not been exhausted after allocating the first student (this would happen if there is only one place available at the desired institution, and the best-ranked student had already been allocated to it). Otherwise, she is allocated to the destination indicated as her second choice. This process is repeated until the lowest-ranked applicant has been allocated to her highest available preference. If none of the six universities indicated by the student are available, the student is assigned to one of the universities which still have available places available after all other students have been allocated. Students can apply during two different sessions within the academic year, fall semester and spring semester, according to the semester in which they would like to go on exchange. These sessions (in which students have the option to apply) are called "application sessions". There are ten different application sessions in the sample used for this paper (spring and fall semester of five academic years).

\section{Dataset}

For each applicant, the following information is available: the preferred partner institutions as expressed on her application form; the position in the student ranking 
compiled by the IRO; the list of available partner institutions, with the number of available places for each year and potential grade requirements; and the institution to which the student was eventually allocated by the IRO.

The dataset is organised as a cross-section of student-university combinations. This generates a large number of observations, 306,580 (the sum of the universities available to every single student). The dependent variable of the empirical model is a dummy variable which takes the value 1 for combination $i j$ if university $j$ has been indicated by student $i$ among her favourite 6 destinations; and 0 otherwise (this variable is called $C$ ). For each student, the rank in the IRO ranking is known. This variable is standardised by dividing it by the total number of applicants in the respective application session; the new, standardised variable is called relrank. A set of universityspecific variables ("strategic characteristics"), which depend on the relationship between the partner institution and SBE, was collected from the IRO files. These variables are the number of available places that the partner institution makes available to SBE students $(a v p)$, a variable indicating whether the GPA of the student is insufficient for admission at the host institution ${ }^{1}$ (labelled graderequisite), and whether or not a partner appears for the first time on the list of partners (new - this variable has been generated because new partners may be chosen less frequently because students did not have the opportunity to learn from the past experience of friends and colleagues).

A number of other university-specific variables have been collected from a number of sources. The position in the THES ranking (thes) was taken from the published rankings (Times Higher Education Supplement 2010) ${ }^{2}$. The accreditation status of each university in each year was obtained from AACSB (2010, private email), and from the websites of partner universities for EQUIS. Other variables were collected from various sources (number of students, year of foundation, etc.), the location (latitude, population of host town, whether it is close to the coast, etc.) and the socioeconomic situation in the countries (price levels, number of internet users per 1,000 inhabitants, etc.). Most of these variables were collected for one year of reference and thus do not vary over time. ${ }^{3}$ All the variables used, and related sources can be seen in Table 5, within Appendix 1.

The sample comprises 152 universities, and is very diverse. Table 1 shows the number of institutions of every region of the world represented in the sample in the first and last year of the analysed period. It also shows the share of universities which were accredited by AACSB or EQUIS. The table shows that many different geographical areas are represented and that a substantial, increasing number of partners is accredited by one of the two organisations. This is paramount for this study, as variations over time for the same university are crucial in the empirical estimations. However, there are two sources of variations over time in the number of accredited institutions. One source is the inclusion of partner universities that had already been accredited when they became partners of SBE. This increases the variation over time, but not within universities. The other source is the accreditation of institutions that were partners of SBE when they received the accreditation. This type of withinuniversity variation is exploited in the empirical part of the paper. 15 universities received an accreditation while they were SBE partners (about $10 \%$ of the sample). The remaining variation in the proportion of accredited universities is due to the inclusion 
Table 1 Number of partner institutions and \% accredited, by region

\begin{tabular}{lllllll}
\hline & \multicolumn{3}{l}{ Academic year $\mathbf{2 0 0 4 / 2 0 0 5}$} & \multicolumn{2}{l}{ Academic } & year $\mathbf{2 0 0 8 / 2 0 0 9}$ \\
\hline Region & $\%$ accr. & $\%$ ranked & Partners & $\%$ accr. & $\%$ ranked & Partners \\
Central Europe & $23.33 \%$ & $20.00 \%$ & 30 & $52.00 \%$ & $20.00 \%$ & 25 \\
Eastern Europe & $0.00 \%$ & $0.00 \%$ & 5 & $0.00 \%$ & $0.00 \%$ & 5 \\
Mediterranean Europe & $13.64 \%$ & $9.09 \%$ & 22 & $26.32 \%$ & $0.05 \%$ & 19 \\
Northern Europe & $54.55 \%$ & $27.27 \%$ & 11 & $62.50 \%$ & $25 \%$ & 8 \\
UK-Ireland & $50.00 \%$ & $50.00 \%$ & 2 & $66.67 \%$ & $66.67 \%$ & 3 \\
AUS-NZ-SA & $80.00 \%$ & $40.00 \%$ & 5 & $50.00 \%$ & $60.00 \%$ & 10 \\
North America & $71.43 \%$ & $14.29 \%$ & 14 & $87.50 \%$ & $58.33 \%$ & 24 \\
Latin America & $20.00 \%$ & $0.00 \%$ & 5 & $42.86 \%$ & $28.57 \%$ & 7 \\
Asia-Pacific & $40.00 \%$ & $40.00 \%$ & 10 & $40.00 \%$ & $46.67 \%$ & 15 \\
Total & $34.62 \%$ & $19.23 \%$ & 104 & $51.72 \%$ & $33.62 \%$ & 116 \\
\hline
\end{tabular}

of accredited universities as partners. The share of partners ranked among the top 200 institutions in the world by the THESR is also relatively high and increasing, but it is lower than the share of accredited partners. However, within-university variation of this measure is more substantial than for accreditations, as the position in the THESR changed for 56 universities while they are partners of SBE (about 37\% of the sample - this also includes institutions appearing in or disappearing from the list of the top 200).

Table 2 reports the descriptive statistics for the institutions in the sample. The last three variables in Table 2 are dummy variables: their value is either 1 (if the statement is true) or 0 (if not). The median partner university has approximately 18,000 students, was established at the beginning of the last century and it is located in a city with almost half million inhabitants. The standard deviation values reported in Table 1 suggest that the variability in the sample is high with respect to these characteristics. A significant share of the partners is private or located on the coast.

The data is particularly valuable for answering the question investigated in this paper. By indicating the preferred partners students make a choice which determines where they will spend several months of their life. As a result, they are highly motivated when filling in the form. This avoids some of the common problems with survey data (see e.g. Bertrand and Mullainhatan, 2003). Another desirable characteristic of this data is that it represents a choice which exhausts all student possible choices. Exchange is compulsory, and the list of possible destinations is pre-determined. Hence, students must pick a number of institutions from a closed set of universities. This is a unique characteristic of this dataset. Most of the studies on student choice in the literature analyse the student enrolment

Table 2 Descriptive statistics of the universities in the sample

\begin{tabular}{llllll}
\hline & $\begin{array}{l}\text { Number of } \\
\text { students }\end{array}$ & $\begin{array}{l}\text { Year of } \\
\text { foundation }\end{array}$ & $\begin{array}{l}\text { Population (host } \\
\text { city/town) }\end{array}$ & $\begin{array}{l}\text { Host city / town } \\
\text { is on the coast }\end{array}$ & $\begin{array}{l}\text { Institution is } \\
\text { private }\end{array}$ \\
\hline Mean & 23,484 & 1849.5 & $1,739,542$ & 0.249 & 0.272 \\
Median & 17,978 & 1906 & 462,786 & 0 & 0 \\
St. Dev. & 27,061 & 178.3 & $2,665,618$ & 0.431 & 0.445 \\
\hline
\end{tabular}


decision and, as a result, they cannot neglect the outside options of individuals (such as going to work or remaining unemployed - see Montgomery, 2002). The fact that the exchange period is compulsory at SBE also implies that there is no self-selection problem of students into the exchange programme. Another advantage of this dataset is that a large number of universities and business schools from different countries are represented in the sample.

On the other hand, it is difficult to assess to what extent the results can be generalized. The students in the sample are all from the same home institution (SBE at Maastricht University), however this does not mean that they are all of the same nationality, as about $40 \%$ of SBE students are not Dutch (SBE, 2012). Furthermore, they take part in an exchange programme, hence their motivations might be different from the motivations of international students enrolling to regular programmes. The population of exchange students is interesting in itself, however, since a substantial part of international student mobility occurs through exchange programmes, especially in Europe. An additional feature of this dataset is that the partner universities are selected by SBE. As a result, they receive a kind of implicit accreditation by SBE. If anything, this means that the effect of variables such as accreditations and rankings should be lower than what it would be if students had chosen from a random sample of universities.

\section{Model}

\section{Modelling students' decision to choose a particular university}

Underlying the choices of the applicants there is a complex strategic game. Every student takes into consideration her expectations about the choices of the students who are ranked better than her. Additionally, in deciding whether to put a university in the list of her favourite six, the student considers all combinations of the other five universities that can be chosen and put on the application form. Hence, it is difficult to choose an appropriate empirical specification. Subsequently the empirical specification will be derived after making a number of strong assumptions. Despite these assumptions, the advantage of starting with the model is that it provides an opportunity to think about crucial control variables. A number of tests will be derived, allowing to assess whether the model is a good approximation of reality.

To choose an appropriate empirical model, it is necessary to define the utility function of an individual $i$ over the possible destinations $j=1, \ldots, J$ available at a given application session (i.e. the function determining the utility that individual $i$ obtains from going to university $j$ - this could be called the intrinsic utility of a destination). The utility function is defined as an exponential function of the characteristics of the university, with individual weights and a random component. The exponential utility function differs from the specification most commonly assumed in the literature, which is linear in its arguments (e.g. Ordovensky, 1995; Montgomery, 2002; Drewes and Michael, 2006) ${ }^{4}$. The exponential function has been chosen for analytical simplicity, as in the following derivations the log of the multiplication between the utility of going to a university and the probability of being able to attend it has been used. The inclusion of the probability of being admitted to a university as a crucial control variable distinguishes this studies from the aforementioned; this is the reason for choosing an 
exponential utility function. Although it satisfies basic properties of utility functions, like monotonicity, its functional form implies risk seeking behaviour over values and over attributes (see e.g. Abbas, 2011, for a discussion of the properties of some multiattribute utility functions). ${ }^{5}$

The characteristics of the destination are divided between observable education quality measures (included in the vector $w_{\mathrm{j}}$, where $t$ indicates the application session), other characteristics of the institution's location (included in the vector $x_{\mathrm{jt}}$ ), a university unobservable effect (labelled $a_{\mathrm{j}}$ ) and a random component which is specific to each individual-university combination $\left(\eta_{\mathrm{ijt}}\right)$.

$$
U_{i j t}=\exp \left[\sum_{k=1}^{K} \omega_{i} \beta_{k} w_{k j t}+\sum_{g=1}^{G} \delta_{g} x_{g j t}+a_{j}+\eta_{i j t}\right]
$$

Where $k=1, \ldots, K$ are the observed education quality characteristics of university $j ; g=1, \ldots, G$ are other observed characteristics; $\beta_{\mathrm{k}}$ and $\delta_{\mathrm{g}}$ are parameters of the model; and $\omega_{\mathrm{i}}$ is a specific weight assigned per individual $i$ to observable education quality characteristics.

Individual $i$ weights this utility by the probability assigned to the likelihood that university $j$ is still available when it is her turn to be allocated, which is called $q_{\mathrm{ijt}}$. From student $i$ 's point of view, the value of including university $j$ in the list of partners (which is called "weighted utility" in this paper) is determined by the multiplication between its intrinsic utility and $q_{\mathrm{ijt}}$. Applying a logarithmic transformation to the weighted utility yields a linear expression (and leaves the order of preference of the individual across universities unchanged, since it is a monotonic transformation):

$$
v_{i j t}=\sum_{k=1}^{K} \omega_{i} \beta_{k} w_{k j t}+\sum_{g=1}^{G} \delta_{g} x_{g j t}+\gamma \ln \left[q_{i j t}\right]+a_{j}+\eta_{i j t}
$$

Where $v_{\mathrm{ijt}}$ is $\log$ weighted utility, and $\gamma$ is the weight given to the probability that $j$ is available when it is her turn to be allocated. ${ }^{6}$

It is assumed that the students indicate the six universities with the highest weighted utility $^{7}$ on their application form. Whether university $j$ is chosen (or not) by $i$ as one of her favourite destinations depends on which other universities can be chosen at time $t$ (competitors of $j$ ). The weaker the competitors (the lower their weighted utility), the higher the probability that $j$ will be chosen by the applicant. Hence, the distribution of weighted utility among the partners matters. Consequently some assumptions are needed to use the latent variable framework (see for example Greene, 2002, Chap. 23) to justify the use of logit or probit. For example, assume that the weighted utility of the universities considered by an individual $i$ is normally distributed. The average is allowed to vary across periods and individuals, as well as the standard deviation. Furthermore, assume that the six universities that a student can choose represent a constant fraction $\rho$ of the total number of partners available at time $t$. Hence, given the parameters of the normal distribution, it is possible to identify a threshold for the weighted utility of university $j$, above which $j$ will be chosen by student $i$. For example, if $\rho$ is approximately equal to 5\% (as it is the case in the dataset used in this paper), then university $j$ will be chosen if its weighted utility is 
higher than approximately two standard deviations above the mean of weighted utility of the universities available to student $i$. More generally, university $j$ enters the list of students $i$ 's favourite six universities if:

$$
v_{i j t}>\mu_{v i t}+\sigma_{v i t} \phi(\rho)
$$

Where $\mu_{\mathrm{vit}}$ is the mean of $v_{\mathrm{ijt}}$ for the different alternative universities available to individual i, $\sigma_{\text {vit }}$ is its standard deviation; and $\phi(\rho)$ is the standard normal probability distribution function. University $j$ is chosen by individual $i$ if:

$$
\sum_{k=1}^{K} \omega_{i} \beta_{k} w_{k j t}+\sum_{g=1}^{G} \delta_{g} x_{g i t}+\gamma \ln \left[q_{i j t}\right]+a_{j}+\eta_{i j t}-\sum_{k=1}^{K} \omega_{i} \beta_{k} \bar{w}_{k t}-\sum_{g=1}^{G} \delta_{g} \bar{x}_{g t}-\bar{a}_{t}-\gamma \overline{\ln \left[q_{i j t}\right]}-\sigma_{v i t} \phi(\rho)>0
$$

Where $\bar{w}_{k t}$ is the average of $w_{\mathrm{kj}}$ over $j$ at a given time $t, \bar{x}_{g t}$ is the average of $x_{\mathrm{gj}}$ over $j$ at a given time $t, \bar{a}_{t}$ is the average of $a_{\mathrm{j}}$ over $j$ at a given time $t$ (notice that, although $a_{\mathrm{j}}$ is assumed to be constant, its average is different for every application session), and $\overline{\ln \left[q_{i j t}\right]}$ is the average of $\ln \left[q_{i j t}\right]$ over $j$ for a given individual $i$.

\section{Empirical strategy}

If the individual random error term, $\eta_{\mathrm{ijt}}$, is normally distributed, then the previous equation can be estimated by a probit model:

$$
\begin{aligned}
\operatorname{Pr}\left[C_{i j t}\right. & =1] \\
& =\Phi\left(\sum_{k=1}^{K} \omega_{i} \beta_{k} w_{k j t}+\sum_{g=1}^{G} x_{g i t}+\gamma \ln \left[q_{i j t}\right]-\sum_{k=1}^{K} \omega_{i} \beta_{k} \bar{w}_{k j t}-\sum_{g=1}^{G} \bar{x}_{g i t}-\gamma \ln \left[q_{i j t}\right]-\bar{a}_{j t}-\sigma_{v i t} \phi(\rho)+a_{j}\right)
\end{aligned}
$$

Where $C_{\mathrm{ijt}}$ is a dummy variable equal to 1 if individual $i$ lists university $j$ among her favourite universities, and 0 otherwise; and $\Phi$ is the standard cumulative normal distribution function. From the equation above, it is apparent that it is necessary to include a number of variables in the estimation.

First of all, it is necessary to include the vectors of observed education quality characteristics $w_{\mathrm{j}}$; to allow for a student-specific weight of these characteristics, the variables in $w_{\text {jt }}$ (i.e., accr, thes and top200) are interacted with relrank (the relative rank of student $i$ in the IRO's ranking, ranging from 0 to 1 ) in the empirical specification. Hence, it is possible to see if the observed education quality measures are taken into consideration by the students, but also whether there are differences between students with higher and lower grades (which are reflected in their position in the IRO's ranking). The vector of other observed characteristics, $x_{j \mathrm{t}}$, and the $\log$ of the probability that university $j$ would actually be available to student $i\left(\ln \left[q_{\mathrm{ijt}}\right]\right.$, hereinafter $\left.\ln q\right)$ must also be included. Although $q_{\mathrm{ijt}}$ cannot be directly observed, it is estimated on the basis of the available data. In order to do so, a dummy variable was generated which is equal to 1 if university $j$ would be available to student $i$ (independently whether student $i$ had actually chosen it), and 0 otherwise. The process of generating a measure for $q_{\mathrm{ijt}}$ is based on 
regressing this dummy variable on a number of covariates (a measure of demand for university $j$ at the top of the ranking, the number of available places at university $j$, squares and interactions between these variables, and a number of control variables) in order to obtain a measure of the predicted probability of $j$ to be available to $i$. More details on how this variable has been constructed are reported in Appendix 2.

To control for the average intrinsic utility of the universities in the list, it is necessary to include a set of dummy variables representing the application session in which student $i$ is applying. However, since the education quality variables are interacted with the individual rankings, it is also necessary to control for the interaction between the average values of accr, thes and top200 (which are called $m_{-}$accr, $m_{-}$thes, and $m_{-}$top200, respectively) in a given application session and the variable relrank. Notice that, according to Equation (5), the coefficient of the interaction between accr (or, equivalently, thes or top200) and relrank should be equal in value, but with opposite signs, to the coefficient of the interaction between $m_{-}$accr (or $m_{-}$thes) and relrank. This can be tested empirically. The average value of $\ln q$ must also be included as a control variable (which is termed $m_{-} \ln q$ ), and its coefficient should be equal to the absolute value of $\ln \left[q_{\mathrm{ijt}}\right]$ (but with the opposite sign). The term $\sigma_{\mathrm{vit}} \phi(\rho)$ is a complex function of the rank of student $i$. Here, it is assumed that $\sigma_{\mathrm{vit}} \phi(\rho)$ changes linearly with relrank. Under this assumption, including the variable relrank in the estimation is sufficient for taking the term $\sigma_{\text {vit }} \phi(\rho)$ into account. It is possible to predict the coefficient of relrank in the empirical estimation. The effect of relrank on $\sigma_{\text {vit }} \phi(\rho)$ is likely to be negative, as the most popular universities will have low probabilities of being available for individuals at the bottom of the IRO's ranking. As a result, their weighted utility will be closer to the weighted utility of less popular universities. Since the effect of $\sigma_{\mathrm{vit}} \phi(\rho)$ on $C_{\mathrm{ijt}}$, according to Equation (5), is negative, the coefficient of relrank should be positive. Hence, the econometric model offers a number of tests that can be performed to evaluate its appropriateness. These tests can be expressed in terms on their null hypotheses: the coefficients of accr, thes, top200, and $\ln q$ should be equal to the opposite of the coefficients of $m_{-} a c c r, m_{-}$thes, $m_{-}$top 200 , and $m_{-} \ln q$; and the coefficient of relrank should be positive. If the null hypotheses are rejected, then the model is unsatisfactory.

Finally, to estimate the effect of time-varying university characteristics while accounting for unobserved heterogeneity $\left(a_{\mathrm{j}}\right)$, it is necessary to include university fixed-effects. This will be done in one specification. However, in another specification the university fixed-effects will be omitted to estimate the effect of time-constant characteristics and to exploit the cross-university variation.

A probit model is used in this paper with and without the inclusion of dummies for every university (the dummies were included to take university fixedeffects into account). As Hilmer (2001) points out, the college attendance decision has usually been modelled by using multinomial logit models, ordered probit or bivariate probit (in the case of modelling only the decision between enrolling to college or not, as in Evans and Schwab, 1995). Running an ordered probit instead of an ordinary probit does not affect the results. Studies using multinomial (or nested) logit models are usually applied to a smaller set of choices than in this paper. The reason can be either that the number of alternatives is small (e.g. 
Oosterbeek et al., 1992), for Dutch economics faculties; (Ordovensky, 1995, for types of higher education institution); or because a small, random sub-sample of national universities is taken (Montgomery, 2002). In this paper, using a simpler model allows considering the full sample of international universities available to the students (which range from approximately 100 to 150 , depending on the application session) and to exploit the time dimension of the dataset by using fixed-effects techniques.

\section{Empirical estimation}

Table 3 presents the results of the probit (with and without university fixed-effects) computed on the basis of the empirical model presented in the preceding section. For every variable and every model, the coefficient and, in brackets, the robust standard error (clustered by university) are reported. The first column reports the results of the first probit regression (Model 1), where all variables listed in Appendix 1 appear as regressors (with the exception of $a v p$, which is used in the calculation of the measure for $q_{\mathrm{ijt}}$ ). The second column reports the results of the regression including university fixed effects (Model 2). In both models, the econometric specification passes all five tests derived at the end of Section 4, since none of the null hypotheses can be rejected at a $10 \%$ confidence level. The coefficient for $\ln q$ (the $\log$ of the probability of university $j$ to be available to student $i$ ) is positive and significantly different from 0 in both models. However, it seems rather low in magnitude, being equal to approximately 0.03 in the model without fixed-effects and 0.07 in the other model. This could be due to a low weight assigned by the student to the probability that an institution is available, or to a severe downward bias due measurement error.

The large number of variables included in Model 1 is likely to generate multicollinearity, so that many coefficients are not significant "(especially for the $\mathrm{x}_{\mathrm{jt}}$ vector which contains the variables not directly related to educational quality the correlation between the variables used is reported in Table 6, within Appendix $3)$. Nonetheless, the coefficients of variables like distance from the equator and GNI per capita in the host country reach statistical significance, and have the expected sign (students prefer richer and warmer places). Among the regional dummies, the only significant ones are for Central Europe (which is negative, perhaps because places in Central Europe are too close to Maastricht to be attractive to SBE students) and North America (which is also negative - the reference category is UK-Ireland). In terms of languages, only the coefficient for French is significantly different from 0 at a $10 \%$ confidence level. Interpreting this coefficient is difficult, as it could indicate that not many students want to learn French, or it could pick up the effects of other characteristics of French-speaking countries. The coefficients of the variables referring to the characteristics of the institution itself (private, students, and foundation) are not significant at a $10 \%$ confidence level, not even jointly.

The only two location characteristics that can be included in the fixed-effects model are GNI per capita and price level of the host country. Once university fixed-effects are controlled for, the sign of the coefficient of GNI per capita is reverted, and the coefficient is not significant anymore. Notice, however, that GNI per capita must be 
Table 3 Results of the regressions

\begin{tabular}{|c|c|c|}
\hline & Model 1 & Model 2 \\
\hline accr & $0.27^{*}(0.055)$ & $0.097(0.072)$ \\
\hline accrank & $-0.19^{*}(0.075)$ & $-0.19 *(0.074)$ \\
\hline m_accrank & $-0.53(0.61)$ & $-0.75(0.63)$ \\
\hline thes & $-0.0023^{*}(0.00077)$ & $-0.0036^{*}(0.0012)$ \\
\hline thesrank & $0.0065^{*}(0.0013)$ & $0.0065^{*}(0.0014)$ \\
\hline m_thesrank & $-0.023 *(0.011)$ & $-0.027^{*}(0.012)$ \\
\hline top200 & $0.0043(0.071)$ & $-0.011(0.073)$ \\
\hline top200rank & $-0.00018(0.00036)$ & $-0.00017(0.00035)$ \\
\hline m_top200rank & $0.000052(0.0012)$ & $-0.00038(0.0013)$ \\
\hline graderequisite & $-1.3^{*}(0.14)$ & $-1.3^{*}(0.11)$ \\
\hline new & $0.15(0.077)$ & $-0.0046(0.056)$ \\
\hline Inq & $0.031^{*}(0.013)$ & $0.074^{*}(0.01)$ \\
\hline m_lnq & $0.008(0.038)$ & $-0.036(0.036)$ \\
\hline relrank & $3.4(2.4)$ & $4.3(2.5)$ \\
\hline pricelevel & $0.16(0.3)$ & $-0.49(0.34)$ \\
\hline gni & $0.000014^{*}(0.000005)$ & $-0.000016(0.000012)$ \\
\hline internetusers & $-0.0052(0.0028)$ & \\
\hline coast & $0.077(0.089)$ & \\
\hline pop & $0(0)$ & \\
\hline private & $-0.048(0.079)$ & \\
\hline foundation & $0.00001(0.00013)$ & \\
\hline latitude & $-0.014^{*}(0.0052)$ & \\
\hline students & $0.00000(0.00000)$ & \\
\hline english & $-0.094(0.095)$ & \\
\hline spanish & $0.22(0.16)$ & \\
\hline french & $-0.18(0.098)$ & \\
\hline asiapacific & $-0.43(0.24)$ & \\
\hline aus-nz-sa & $-0.07(0.15)$ & \\
\hline centraleurope & $-0.33^{*}(0.1)$ & \\
\hline easterneurope & $0.08(0.22)$ & \\
\hline latinamerica & $-0.5(0.33)$ & \\
\hline mediterraneaneurope & $-0.14(0.17)$ & \\
\hline northamerica & $-0.23^{*}(0.11)$ & \\
\hline northerneurope & $0.24(0.13)$ & \\
\hline application round fixed effects & Yes & Yes \\
\hline university fixed effects & No & Yes \\
\hline Nr. of observations & 306580 & 303649 \\
\hline$\%$ of correctly predicted successes & $13.3 \%$ & $18.9 \%$ \\
\hline
\end{tabular}

a. ${ }^{*}$ indicates significance at the $5 \%$ level.

b. In the fixed-effects specification there are 2931 less observations, as 6 universities have been dropped because the time-constant fixed-effect predicts the failure perfectly (i.e., 6 universities have never been chosen).

interpreted as economic growth in Model 2, whereas it was interpreted in terms of level in Model 1. The price level coefficient has the expected negative sign, but is not significant at a $5 \%$ confidence level. 
As expected, the fact that the grade requirement of the host institution exceeds the GPA of the applicant has a large, negative impact on the dependent variable. In these instances the results imply that the average probability of for a university to be chosen by a student decreases by $96-97 \%$ (depending on the model). Whether a university is new on the list of partners, on the contrary, has no significant effect on the probability that it is chosen. This is somewhat surprising, as one might expect that a new university would suffer a penalty because it cannot be recommended by students who went on the exchange in preceding years.

According to both models, accreditations and the position of an institution in the THESR have a positive effect of the probability of choosing a university for students with high academic achievement. However, the effect of accreditations, when university fixed-effects are included, is not significantly different from 0 (its p-value is $18 \%$ ). The effect is lower for students who are not ranked at the top of the IRO's ranking, and it is (surprisingly) negative for students at the bottom of the ranking. To understand the implied magnitude of the coefficients in the two models, Table 4 reports the average of the estimated effect of gaining an accreditation or improving by one position in the THESR for a student ranked in the top, median or lowest position in the IRO's ranking (the effect of being included in the THESR top 200, as displayed by Table 3, is not substantial, hence it has not been reported). The figures in Table 4 have been computed as the average predicted percentage change (across all eligible universities) of the probability to be chosen by a student in a particular position in the IRO's ranking. According to Model 2, a university increases its probability to be chosen by the "best SBE student" by $24 \%$ (from 5.1 to $8.5 \%$ ) by gaining an accreditation, and by $0.8 \%$ by improving its standing in the THESR by one position. The increase of the probability to be chosen by the median student is rather modest, however, and is negative for the lowest-ranked student. The effects estimated with Model 1 are larger (or closer to 0 , if negative) for accreditations, but less positive for the THESR. ${ }^{11}$

An interesting question is whether the inclusion of university fixed-effects significantly increases the ability of the model to predict the outcome of students' choice. Testing whether this is the case is not straightforward, however, as the two models presented in Table 3 are not nested in each other. To run the test, a measure of correctly predicted outcomes was generated. First, the predicted probabilities were computed according to the two models. Subsequently the available partner institutions were ranked according to their predicted probability of being indicated among the favourites for each applicant. The universities with the highest predicted probability for each applicant were classified as "predicted success". ${ }^{12}$ The other observations were classified as "predicted failures". Combining this information with the actual choices of the students, it is possible to compute the number of correctly predicted successes (observations for which the dependent variable takes

Table 4 Average increase of the probability that a university is chosen by a student in the top, median, or bottom position in the IRS student ranking in percent

\begin{tabular}{lllll}
\hline & accr - Model 1 & accr - Model 2 & thes - Model 1 & thes - Model 2 \\
\hline $1^{\text {st }}$ & $75.3 \%$ & $24.0 \%$ & $0.5 \%$ & $0.8 \%$ \\
Median & $44.9 \%$ & $1.0 \%$ & $-0.2 \%$ & $0.1 \%$ \\
Last & $19.7 \%$ & $-17.6 \%$ & $-0.9 \%$ & $-0.6 \%$ \\
\hline
\end{tabular}


a value of 1 and which are classified as predicted success) and failures, and the number of wrong predictions. With this information, it is possible to run a Pearson's Chi Square test to ascertain whether the two models are significantly different from each other in terms of predictive power, and whether they differ from a hypothetical model which includes only a constant (random prediction). Model 1 differs significantly from the random-prediction model at any conventional confidence level $\left(\chi^{2}(1)=2287\right)$, and Model 2 in turn differs significantly from Model 1 $\left(\chi^{2}(1)=484\right) .{ }^{13}$ In Table 3 the share of correctly predicted successes is reported as a measure of fit. For a random prediction, this measure takes a value of $5.1 \%$ (equal to the proportion of successes in the sample). The two models reported in Table 3 score substantially better, correctly predicting $13.3 \%$ and $18.9 \%$ of successes.

\section{Conclusions}

This paper analyses the determinants of international exchange students' choices of possible destination for their study period abroad. The focus of the paper is on available measures of education quality in international higher education: the professional accreditations for business schools, AACSB and EQUIS, and the Times Higher Education Supplement Ranking (THESR). The data has been made available by Maastricht University School and Business and Economics (SBE).

The results indicate that factors related both to the quality of education (professional accreditations and international rankings) and to characteristics of the university location (e.g. being on the coast, proximity to the Equator) affect students' choices, even when controlling for university fixed-effects (although the effect of professional accreditations in this case is not significant at a 5\% confidence level). However, the estimated effect is not the same across all students, being positive for students with high academic achievement, and negative for students with low academic achievement.

The average effect of accreditations and rankings is large at the top of the student distribution, even when controlling for fixed effects: an accreditation increases the probability of a university to be chosen by $24 \%$, and an improvement in the THESR by one position by $0.8 \%$. However, the effect on the median student is very small ( $1 \%$ and $0.1 \%$, respectively), and the estimated effect becomes negative for the students with the lowest academic achievement ( $-18 \%$ and $-0.6 \%)$.

These findings apply directly to the preferences of international exchange students, which (at least in Europe) constitute a substantial part of the overall student mobility. The results partly confirm what one would expect based on human capital theory and on the fact that the exchange period is an important time in an individual's development of professional and inter-personal skills: students prefer schools which are expected to offer good quality education. As suggested by previous research, other characteristics of the destination also play an important role. However, the fact that rankings and accreditations have a negative effect on the probability of a university to be chosen by students with low grades requires an explanation. It may be that students with low grades self-select into institutions with lower academic standards. Alternatively, it could be that students with low grades perceive that the probability of finding a place in an institution offering an education of good quality is lower than it can be predicted on the basis of available data (so that a negative effect of rankings and accreditation is found even after controlling for probability). 
The results have strong implications for university managers: by improving their standing in international rankings, their institution becomes more appealing to top international students. The effect of accreditations on attracting top students also appears large, but conclusions cannot be reached at the same confidence level. Implications are less clear for policy makers. Professional accreditations and international rankings can be seen as a means to reduce students' uncertainty over the quality of foreign institutions and, as a result, to facilitate student mobility. Student mobility, in turn, is a useful tool for a number of policy objectives which are given high priority in the European area, such as labour mobility and cultural integration. However, the signal sent by international rankings and accreditations does not appear relevant for all students. In order to stimulate international mobility among students with below-average academic achievement, it might be necessary to look for more effective tools.

\section{Endnotes}

${ }^{1}$ The IRO files only report the grade requirements for each university and the GPA for a number of students. One problem is that for most semesters, there is no information on students' GPA unless this was higher than 7.5. In order to have a measure of GPA for students for whom this variable cannot be observed directly, a predicted value was computed. The student's GPA was regressed on a quartic function of relrank, a fall semester dummy and a time trend, using observations from the three semesters for which the GPA is available for all students (spring 2005, fall 2007, and spring 2008), obtaining $R^{\wedge} 2=91 \%$. Then the missing observations for GPA were substituted by the predicted values based on this regression. Note further that about $90 \%$ of universities do not impose any grade requirement, and that the fact that a partner institution may have a grade requirement higher than the GPA of the student does not prevent the student to name that university as one of her favourites.

${ }^{2}$ An arbitrary value of 200 was used if a university did not appear in the first 200 positions of the ranking. Since a dummy had been included indicating whether a university appears among the top 200 or not, the arbitrary value which is chosen is irrelevant in estimating the coefficient of the variable thes.

${ }^{3}$ Student numbers, for example, were collected according to the submission by the university to Quacquarelli Sismond (2009), or to the university website, and not collected for each year.

${ }^{4}$ Oosterbeek et al. (1992) assume the utility of attending a university to be linear in the $\log$ of the only university characteristic included in the model (future expected wage), which is similar to the assumption of an exponential utility function made here.

${ }^{5}$ As an alternative, a multiplicative function of the Cobb-Douglas type could have been used. However, it would not have been possible to work with logs, as many empirical variables can take the value 0 .

${ }^{6}$ A benchmark value for $\gamma$ could be 1 . This would mean that a university's weighted utility is equal to the intrinsic value of the university times the probability that the student would be allocated a place there. However, the weight the student assigns to $q_{\mathrm{ijt}}$ is likely to be lower, since not obtaining a place at a specific university does not entail that the student obtains zero utility (she could be allocated to another university in the list, or she may receive a good allocation even after all other students have been allocated). For example, consider a student who has a satisfactory option among the partner institutions, 
with a very high probability of having available places left. This student could choose the other universities in the list regardless of the probability of available spaces, since she is already sure of achieving an acceptable outcome (see also Endnote 7).

7 This assumption cannot hold exactly. It can be shown that a risk-neutral student would mention the university with maximum weighted utility among her favourite six, but would not necessarily choose all six universities with the highest weighted utility (in some cases, a risk-neutral student might choose universities with very high intrinsic utility despite a relatively low weighted utility).

8 The (average) share of universities listed by applicants among the favourite six across all ten application sessions included in the analysis ranges from $4.5 \%$ to $6.5 \%$, with an average of $5.1 \%$ and without specific trends.

${ }^{9}$ The interpretation of interaction effects in logit and probit models present some challenges (e.g. Chunrong and Norton, 2003) which this paper does not deal with. The reason is that the interest in this study lies in the effect of the variable contained in the vectors $w_{j \mathrm{t}}$ and $x_{\mathrm{jt}}$, and not in the interaction effect in itself.

${ }^{10}$ Accounting for fixed effects by including dummies can be problematic when using probit, because the number of variables included becomes too large relative to the number of observations (see Greene, 2002, Chap. 23). In this case, this is not a problem, since there are 152 universities in the sample, and 306,580 observations.

${ }^{11}$ The effects reported in Table 4 are estimated under the assumption that an EQUIS or an AACSB accreditation have the same effect. It is possible to estimate the two effects separately, and the results point to a stronger effect of the AACSB accreditation. However, these estimates are based on a very small number of universities which actually changed their accreditation status while being SBE partners, as noted in Section 3. For this reason, they are not reported in this paper.

${ }^{12}$ Usually, an applicant chooses six universities. In that case, the six universities with the highest predicted probability for that applicant are classified as predicted success. Applicants are allowed to list fewer than six universities, and in some cases they do. In that case, the number of universities equal to the number of universities listed by the student were classified as predicted success.

13 These statistics seem unusually high. However, the p-values generated by the test compare well to those of a Wald test for restrictions that can be tested both with a Wald test and with the test used in this paper.

\section{Appendix 1}

In order to account for the relationship between the partner institutions and SBE (e.g. whether they have been partners before, or whether the partner institutions requires SBE to send only students with a minimum GPA) and for characteristics of the partner institutions and their locations (e.g. number of students in the university, or price level in the host country) a number of variables have been collected from various sources. The variable names, together with a short description and the data sources, are reported in Table 5.

\section{Appendix 2}

\section{Constructing $q_{\mathrm{ijt}}$}

The probability that a university $j$ is actually available to student $i$ (i.e., there are still places left at that university when it is the turn of student $i$ to be allocated) is a crucial 
Table 5 Variables definition and sources

\begin{tabular}{|c|c|}
\hline Variable & Description / source \\
\hline C & Dummy ( $=1$ if the observation corresponds to a university which has been chosen by the student) / Based on SBE data \\
\hline accr & $\begin{array}{l}=1 \text { if the institution has one accreditation, either AACSB or EQUIS; }=2 \text { if it has both; }=0 \text { otherwise / Based on AACSB data (received by email on request) and } \\
\text { university websites }\end{array}$ \\
\hline thes & $\begin{array}{l}\text { Position of the institution in the latest THESR (for every year, rank is set equal to } 200 \text { if the institution does not appear among the } 200 \text { top-ranked institutions) / } \\
\text { Based on THES (2010) }\end{array}$ \\
\hline top200 & Dummy ( $=1$ if the institution has been ranked in the top 200 in the latest THESR) \\
\hline avp & Available places at the institution in the relevant application session / Based on SBE data \\
\hline relrank & Relative position of the student in the IRO's ranking / Based on SBE data \\
\hline graderequisite & Dummy ( $=1$ if grade requisite of university $j>$ GPA of university $i$, as predicted through an OLS regression) / Based on SBE data \\
\hline new & Dummy ( $=1$ if the institution appears in the partner list for the first time) / Based on SBE data \\
\hline coast & Dummy (=1 if host city / town is located on the coast) / Based on National Geographic (2012) \\
\hline pop & Population of the host city / town in 2007 or nearest year / UNESCO (2007) for towns / cities with more than 100,000 inhabitants; World Gazetteer (2009) otherwise \\
\hline foundation & Year of foundation of the institution / Universities' websites \\
\hline latitude & Latitude of the host city / town (absolute value) / Based on National Geographic (2012) \\
\hline students & Number of students at the institution in most recent year available / QS Ltd (2009); universities' website when missing \\
\hline english & Dummy ( $=1$ if the institution is located in an English-speaking region) \\
\hline spanish & Dummy (=1 if the institution is located in a Spanish-speaking region) \\
\hline french & Dummy (=1 if the institution is located in a French-speaking region) \\
\hline internetusers & Internet users per 100 people in the host country / World Bank (2012); Central Intelligence Agency (CIA 2009) for Taiwan \\
\hline pricelevel & Price level in the host country relative to the US / World Bank (2012); Taiwanese Council for Economic Planning and Development (TCEPD) (TCEPD 2009) for Taiwan \\
\hline gni & GNI per capita at PPP / World Bank (2012); Taiwanese Council for Economic Planning and Development (TCEPD) (TCEPD 2009) for Taiwan \\
\hline private & Host institution is private / university websites \\
\hline asiapacific & Dummy ( $=1$ if the institution is located in Asia, excl. Turkey, or Oceania, excl. Australia and New Zealand) \\
\hline aus-nz-sa & Dummy ( $=1$ if the institution is located in Australia, New Zealand or South Africa) \\
\hline centraleurope & Dummy (=1 if the institution is located in Central Europe - Austria, Belgium, Germany, France, Switzerland, excl. towns located on the Mediterranean coast) \\
\hline easterneurope & Dummy ( $=1$ if the institution is located in Eastern Europe - Czech Republic, Estonia, Hungary, Poland) \\
\hline latinamerica & Dummy (=1 if the institution is located in Latin America) \\
\hline mediterraneaneurope & Dummy ( $=1$ if the institution is located in Mediterranean countries - France for towns located on the Mediterranean coast, Italy, Portugal, Spain, Turkey) \\
\hline northamerica & Dummy (=1 if the institution is located in Canada or US) \\
\hline northerneurope & Dummy ( $=1$ if the institution is located in Northern Europe - Denmark, Finland, Norway, Sweden) \\
\hline
\end{tabular}


control variable. Although it cannot be directly observed, it is possible to estimate it on the basis of the available data.

First of all, it is possible to know whether a given university $j$ would be available to student $i$, had she chosen it. This is because the ranking of students is known, as is the institution to which each student is allocated and the number of available places at each institution. As a result, a dummy variable can be generated which is equal to 1 if university $j$ is available to student $i$, and to 0 otherwise. The first step in the process of generating a measure of $q_{\mathrm{ijt}}$ is to regress this dummy variable (called $R_{\mathrm{ijt}}$ ) on a number of covariates to obtain a measure of the predicted probability of $j$ to be available to $i$. So, for each individual $i$ the following equation is estimated:

$$
R_{i j t}=\pi_{0 i}+\sum_{h=1}^{H} \pi_{h i} D_{h j t}
$$

Where the parameters $\pi_{0 \mathrm{i}}$ and $\pi_{\mathrm{hi}}, h=1, \ldots, H$, are student-specific and the universityspecific regressors $\left(D_{1 \mathrm{jt}}, \ldots, D_{\mathrm{hjt}}\right)$ include: the share of students, among those occupying the top 40 positions of the IRO's ranking, listing university $j$ as their favourite two universities (a measure of demand at the top of the distribution, called top402); its square; the available places at university $j$ at time $t\left(a v p_{j t}\right)$, and their square; the multiplication between avp and top402; accr, thes, latitude and pricelevel; and a set of dummy variables indicating the macro-region where university $j$ is located (see Appendix 1; all dummies for European regions where condensed to a dummy which is equal to 1 if the university is European, to reduce the total number of variables in the model). A linear probability model was used because the dependent variable $\left(R_{\mathrm{ijt}}\right)$ is constant (equal to 1 ) for a number of top-ranked students. Hence, using a logit or probit model would have eliminated a number of observations. One regression was run for every student in the sample, for a total of 2,970 regressions. The average $\mathrm{R}$ squared is $47 \%$. The predicted value of $R_{\mathrm{ijt}}$ according to this regressions can be used as a measure for $q_{\mathrm{ijt}}$. Note that the predicted value of $R_{\mathrm{ijt}}$ varies across students (as the parameters in the estimated equation are student-specific) and across universities (as the regressors are university-specific). However, it is not always positive. This implies that it is not possible to take the $\log$ of $q_{\mathrm{ijt}}$, as required by Equation (5). Hence, as a second step of the procedure, a logistical regression of $\mathrm{R}_{\mathrm{ijt}}$ over its predicted values was run, and the predicted probability on the basis of this regression was used as a measure of $q_{\mathrm{ijt}}$.

The variable top 402 has been chosen because students in the first positions of the IRO's ranking are likely to choose the first universities in their list without strategic considerations related to their probability of actually being available. This avoids introducing endogeneity in the measure of $q_{\mathrm{ijt}}$ and, as a result, in the estimation of Equation (5).

Choosing different variables as the regressors in the first step of the procedure does not affect the results that have been presented substantially. Using the fitted values of the first step as a proxy for $\ln \left[q_{\mathrm{ijt}}\right]$ in the estimation of Equation (5) does not affect the results substantially either.

\section{Appendix 3}

Estimating precisely the coefficients of the variables used in the empirical estimation is sometimes difficult, because of the collinearity between some of these variables. In Table 6, the correlation between the variables used in the estimation (with the exception of 
Table 6 Correlation among the variables used in the estimations

\begin{tabular}{|c|c|c|c|c|c|c|c|c|c|c|c|c|c|c|c|c|c|c|c|}
\hline & accr & accrank & m_accrank & thes & thesrank & m_thesrank & new & graderequisite & $\operatorname{lnq}$ & m_lnq & relrank & gni & pricelevel & Internet users & coast & pop & private & established & latitude \\
\hline accr & 1.000 & & & & & & & & & & & & & & & & & & \\
\hline accrank & 0.775 & 1.000 & & & & & & & & & & & & & & & & & \\
\hline m_accrank & 0.027 & 0.407 & 1.000 & & & & & & & & & & & & & & & & \\
\hline thes & -0.189 & -0.144 & -0.023 & 1.000 & & & & & & & & & & & & & & & \\
\hline thesrank & -0.098 & 0.207 & 0.742 & 0.509 & 1.000 & & & & & & & & & & & & & & \\
\hline m_thesrank & -0.014 & 0.377 & 0.927 & 0.009 & 0.800 & 1.000 & & & & & & & & & & & & & \\
\hline new & -0.065 & -0.048 & 0.025 & -0.016 & 0.005 & 0.010 & 1.000 & & & & & & & & & & & & \\
\hline graderequisite & 0.022 & 0.048 & 0.089 & -0.140 & -0.047 & -0.049 & -0.019 & 1.000 & & & & & & & & & & & \\
\hline $\operatorname{lnq}$ & -0.179 & -0.312 & -0.320 & 0.207 & -0.206 & 0.413 & -0.006 & -0.027 & 1.000 & & & & & & & & & & \\
\hline m_lnq & 0.046 & -0.262 & -0.643 & -0.037 & -0.664 & 0.830 & 0.000 & 0.066 & 0.497 & 1.000 & & & & & & & & & \\
\hline relrank & 0.002 & 0.361 & 0.887 & -0.001 & 0.709 & -0.886 & 0.000 & 0.089 & -0.340 & -0.683 & 1.000 & & & & & & & & \\
\hline gni & 0.241 & 0.181 & 0.029 & -0.272 & -0.150 & 0.025 & -0.067 & -0.032 & 0.019 & 0.077 & 0.003 & 1.000 & & & & & & & \\
\hline pricelevel & 0.109 & 0.082 & 0.027 & -0.071 & -0.048 & 0.021 & -0.034 & -0.052 & 0.254 & 0.059 & 0.002 & 0.666 & 1.000 & & & & & & \\
\hline internetusers & 0.155 & 0.116 & 0.036 & -0.207 & -0.121 & 0.028 & -0.092 & -0.030 & 0.075 & 0.090 & 0.003 & 0.806 & 0.683 & 1.000 & & & & & \\
\hline coast & 0.107 & 0.088 & 0.009 & -0.229 & -0.108 & -0.010 & 0.053 & 0.028 & -0.265 & -0.010 & 0.000 & 0.091 & -0.027 & 0.022 & 1.000 & & & & \\
\hline pop & 0.004 & 0.006 & 0.016 & -0.177 & -0.088 & 0.002 & 0.032 & 0.075 & -0.252 & 0.014 & 0.001 & -0.379 & -0.572 & -0.354 & 0.232 & 1.000 & & & \\
\hline private & 0.027 & 0.022 & 0.006 & 0.242 & 0.123 & 0.004 & 0.007 & -0.015 & -0.013 & 0.007 & 0.000 & -0.060 & -0.138 & -0.091 & -0.156 & 0.150 & 1.000 & & \\
\hline established & 0.252 & 0.196 & -0.007 & 0.104 & 0.046 & 0.010 & 0.056 & 0.044 & -0.161 & 0.010 & 0.000 & -0.037 & -0.175 & -0.065 & 0.140 & 0.187 & 0.230 & 1.000 & \\
\hline latitude & -0.138 & -0.106 & -0.005 & 0.156 & 0.081 & -0.007 & -0.044 & -0.064 & 0.377 & -0.012 & -0.001 & 0.228 & 0.660 & 0.423 & -0.255 & -0.523 & -0.185 & -0.281 & 1.000 \\
\hline students & -0.165 & -0.129 & 0.004 & -0.105 & -0.049 & -0.003 & -0.019 & -0.007 & -0.130 & 0.001 & 0.000 & -0.169 & -0.213 & -0.136 & 0.117 & 0.347 & -0.277 & -0.196 & -0.055 \\
\hline
\end{tabular}


dummy variables like those indicating geographical location or language spoken) is reported. The high correlation between, for example, gni and internetusers, or pop and latitude, can make it difficult to estimate the respective coefficients precisely.

\section{Competing interests}

The IZA Journal of European Labor Studies is committed to the IZA Guiding Principles of Research Integrity. The author declares that he has observed these principles.

\section{Acknowledgements}

I thank Maastricht University's School of Business and Economics for providing the data on students' applications. Comments and suggestions from several seminar and conference participants have been most helpful. I thank Prof. Christopher Leslie Gilbert and Prof. Andries de Grip for the support given during different phases of the development of this paper, and two anonymous reviewers for their useful comments.

Responsible Editors: Martin Kahanec and Jo Ritzen

Received: 12 March 2013 Accepted: 17 June 2013

Published: 5 July 2013

\section{References}

Abbas A (2011) Decomposing the cross derivatives of a multiattribute utility function into risk attitude and value. Decision Anal 8:103-116

Bertrand M, Mullainathan S (2003) Do People Mean What They Say? Implications for Subjective Survey Data. Am Econ Rev 91:67-72

Black D, Smith J (2004) How robust is the evidence on the effects of college quality? Evidence from matching J Econometrics 121:99-124

Bracht O, Engel C, Janson K, Over A, Schomburg H (2006) The Professional Value of Erasmus Mobility. Eu Commission, Brussels

Brewer D, Eide E, Ehrenberg R (1999) Does it pay to attend an elite private college? Cross-cohort evidence on the effects of college type earnings. J Hum Res 35:104-123

Burn B, Cerych L, Smith A (1990) Study Abroad Programmes. Jessica Kingsley Publishers, London

Chunrong A, Norton E (2003) Interaction terms in logit and probit models. Econ Letters 80:123-129

CIA (2009) The World Factbook. www.cia.gov/library/publications/the-world-factbook

Drewes T, Michael C (2006) How do students choose a university? An analysis of applications to universities in Ontario, Canada. Res High Educ 47:781-800

Elliott C (2012) The international market for MBA qualifications, Paper presented at the Conference of the Scottish Economics Society., Perth

Commission E (2006) Delivering on the Modernisation Agenda for Universities: Education, Research and Innovation. EU Commission, Brussels

Commission E (2009) Green Paper - Promoting the learning mobility of young people. EU Commission, Brussels

Evans W, Schwab R (1995) Finishing high school and starting college: Do catholic schools make a difference? Q J Econ 110:941-974

Gibbons S, Vignoles A (2012) Geography, choice, and participation in higher education in England. Reg Sci Urban Econ 42:98-113

Greene W (2002) Econometric analysis. Pearson Prentice Hall, Upper Saddle River

Hazelkorn E (2008) Learning to Live with League Tables and Rankings: The Experience of Institutional Leaders. High Educ Policy 21:193-215

Hilmer M (2001) A comparison of alternative specifications of the college attendance equation with an extension to two-stage selectivity-correction models. Econ Educ Rev 20:263-278

Kelo M (2006) Support for International Students in Higher Education. ACA Papers on International Cooperation in Education, Brussels

Kong Q, Veall M (2002) Does the Mcleans's Ranking Matter? Canadian Public Policy 31(3):231-242

Llewellyn-Smith C, McCabe V (2008) What Is the Attraction for Exchange Students: the Host Destination or Host University? J Tourism Res 10:593-610

Lock A (1999) Accreditation in Business Education. Quality Assur Educ 7:68-76

SBE (2012) Internationalisation. www.maastrichtuniversity.nl/web/show/id=3665998/langid=42

Marginson S (2007) Global University Rankings: Implications in general and for Australia. J High Educ Policy Manag 29:131-142

Mclnnis C, Coates H, Hooper C, Jensz F, Vu T (2004) Study Abroad and Study Exchange Systems in Industrialised Countries. AEl, Canberra

Mcmahon M (1992) Higher education in a world market: A historical look at the global context of international study. High Educ 24:465-482

Monks J, Ehrenberg J (1999) US News and World Report College Rankings: Why they Matter. Change 31:42-51

Montgomery M (2002) A nested logit of the choice of a graduate business school. Econ Educ Rev 21:471-480

National Geographic (2012) Maps. www.nationalgeographic.com

Oosterbeek H, Groot W, Hartog J (1992) An empirical analysis of university choice and earnings. De Economist 140:293309

Ordovensky J (1995) Effects of institutional attributes on enrollment choice: Implications for postsecondary education. Econ of Educ Rev 14:335-350

Quacquarelli Sismond (2009) Online database. www.topuniversities.com

Ritzen J (2010) A Chance for European Universities. Amsterdam University Press, Amsterdam 
Rodriguez-Gonzalez C, Bustillo-Mesanza R, Mariel P (2011) The determinants of international student mobility flows: an empirical study on the Erasmus programme. High educ 62:413-430

Saisana M, D'Hombres B, Saltelli A (2011) Rickety numbers : Volatility of university rankings and policy implications. Res Policy 40:165-177

Sciglimpaglia D, Medlin C, Toole H, Whittenburg G (2005) Business Schools Accreditations, A Survey of Australian Academics. Paper presented at the 20th Small Enterprise Conference, New Zealand

Soo K, Elliott C (2010) Does price matter? Overseas students in UK higher education. Econ Educ Rev 29:553-565

TCEPD (2009) Taiwan statistical databook. www.cepd.gov.tw

Teichler U (2004) Temporary Study Abroad: the life of ERASMUS students. Eu J Educ 39:395-408

Teichler U, Janson K (2007) The professional value of temporary study in another European country: Employment and work of former ERASMUS students. J Studies Internat Educ 11:486-495

Thissen L, Ederveen S (2006) Higher education: Time for coordination on a European level? CPB NL Bureau for Econ Policy. Anal, The Hague

Times Higher Education Supplement (2010) The world university rankings. www.timeshighereducation.co.uk

Unesco (2007) Demographic Yearbook. United Nations, New York

Woodhouse D (1999) Quality and Quality Assurance. In: Knight J, de Wit H (eds) Quality and Internationalisation in Higher Education. OECD, Paris

World Bank (2012) The World Bank open data. www.worldbank.org. Accessed: September 2012

World Gazetteer (2009) Population data and statistics. www.world-gazetteer.com

doi:10.1186/2193-9012-2-5

Cite this article as: Marconi: Rankings, accreditations, and international exchange students. IZA Journal of European Labor Studies 2013 2:5.

Submit your manuscript to a SpringerOpen ${ }^{\circ}$ journal and benefit from:

- Convenient online submission

- Rigorous peer review

- Immediate publication on acceptance

- Open access: articles freely available online

- High visibility within the field

- Retaining the copyright to your article

Submit your next manuscript at $\gg$ springeropen.com 